\title{
Comparative efficacy of tamsulosin versus nifedipine for distal ureteral calculi: a meta-analysis
}

\author{
This article was published in the following Dove Press journal: \\ Drug Design, Development and Therapy \\ 29 March 2016 \\ Number of times this article has been viewed
}

\author{
Hai Wang \\ Li Bo Man \\ Guang Lin Huang \\ Gui Zhong Li \\ Jian Wei Wang
}

Department of Urology, Beijing Jishuitan Hospital, Beijing, People's

Republic of China
Correspondence: Hai Wang Department of Urology, Beijing Jishuitan Hospital, 3I East Xinjiekou Street, Beijing 100035, People's Republic of China

Tel +86 I0 585I 6688

Email haiwang616@sina.com
Objective: The aim of this study was to systematically compare the therapeutic effect and safety of tamsulosin with nifedipine in medical expulsive therapy for distal ureteral calculi.

Methods: Databases, including PubMed, EMBASE, the Cochrane Library, and Clinical Trial Register Centers, were comprehensively searched. Relevant randomized controlled trials (RCTs) were selected, and quality assessment was performed according to the Cochrane Handbook. RevMan software was used to analyze the outcome measures, which consisted of expulsion rate, expulsion time, and complications.

Results: Twelve RCTs consisting of 4,961 patients were included (tamsulosin group, 2,489 cases; nifedipine group, 2,472 cases). Compared with nifedipine, tamsulosin significantly increased the expulsion rate (risk ratio $=1.29,95 \% \mathrm{CI}[1.25,1.33], P<0.0001$ ) and reduced the expulsion time (standard mean difference $=-0.39,95 \%$ CI $[-0.72,-0.05], P=0.02$ ). Regarding safety, tamsulosin was associated with fewer complications than nifedipine (risk ratio $=0.45,95 \%$ CI $[0.28,0.72], P=0.0008$ ), and further subgroup analysis showed that tamsulosin was associated with a lower risk of both mild and moderate-to-severe complications.

Conclusion: On the bias of current evidence, tamsulosin showed an overall superiority to nifedipine for distal ureteral calculi $<10 \mathrm{~mm}$ in aspects of expulsion rate, expulsion time, and safety. Tamsulosin was supposed to be the first drug to be recommended to patients willing to receive medical expulsive therapy.

Keywords: tamsulosin, nifedipine, medical expulsive therapy, MET, lower urinary calculi

\section{Introduction}

As one of the most common causes of serious abdominal pain in the emergency department, urinary calculi affects $\sim 5 \%-10 \%$ of the whole populations in the world. ${ }^{1}$ The lifetime risk is $\sim 10 \%-15 \%$ in the developed world and would be higher to $20 \%-25 \%$ in the Middle East. ${ }^{2}$ Moreover, it is also a disease with high recurrence rates of $25 \%-50 \%$ during $5-10$ years and $75 \%$ during 20 years of follow-up. ${ }^{2,3}$ Among these cases, $20 \%$ of them were ureteral calculi, which was estimated to result in $>1$ million emergency department visits per year in the USA. ${ }^{4}$

With decreased invasion and cost, open and laparoscopic surgery, ureteroscopy, percutaneous nephrolithotomy, extracorporeal shock wave lithotripsy (ESWL), and medical expulsive therapy (MET) were subsequently developed to treat ureteral calculi. Based on specific characters, such as the location/size of calculi and the demand of patients, the treatments were gradually or jointly adopted. In the last decade, many studies have focused on the ability of MET to facilitate distal ureteral calculi (DUC) and confirmed its efficacy and safety either with ESWL or without ESWL compared with control. ${ }^{5,6}$ Although MET could not achieve calculi-free rate as high as ureteroscopy, the 
administrated drugs in MET would significantly reduce the medical cost and prevent an unnecessary invasive procedure. ${ }^{7}$ Besides, previous MET would not have any negative influence on the further minimally invasive surgery, and hence more and more attentions were gained in recent years. ${ }^{8}$

Obviously, both alpha-receptor blocker and calciumchannel blocker had pharmacological effects of smooth muscle relaxation in ureteral tract. Among the drugs administrated in MET, tamsulosin and nifedipine were recommended by the European Association of Urology Guidelines and currently are the most common drugs adopted in clinical practice and research. ${ }^{9,10}$ In order to clarify the difference between the two drugs, a series of randomized controlled trials (RCTs) were designed to compare the therapeutic efficacy and safety. However, the choice for a urological surgeon seemed to be still confusing due to the inconsistent results and uncertain conclusions. ${ }^{11-22}$ Therefore, we conducted a meta-analysis to systematically evaluate the comparative effects and safety between tamsulosin and nifedipine for DUC in MET.

\section{Methods}

\section{Literature search}

A comprehensive search was performed to identify all RCTs that compared the efficacy and safety of tamsulosin with nifedipine in MET for DUC. Online databases, including PubMed, EMBASE, the Cochrane Library, Clinical Register Centers, and Chinese Academic Databases, were searched up till October 2015 without language limitation. Search terms used in PubMed were as follows: (tamsulosin OR terazosin OR doxazosin OR cardura OR hytrin OR urimax OR flomaxtra OR flomax OR alfuzosin OR naftopidil OR silodosin OR alpha-blocker OR $\alpha$-blocker OR alpha blocker) AND (nifidipine OR ecodipine OR oxcord OR procardia OR nifelat OR corinfer OR calcium channel blocker) AND (calculi OR stone). Related articles and citations of the search results were complementally screened. Google Scholar and Baidu Scholar were searched using subject headings for the last published articles.

\section{Inclusion and exclusion criteria}

After removing duplication, two researchers (LB Wang and GL Huang) independently reviewed the literature search results for eligibility by reading the abstracts. Preliminary inclusion criteria were based on the study design, participants, comparison, and outcome measures. 1) Only prospective RCTs were included. 2) Participants were patients with DUC diagnosed by ultrasonographically and/or radiologically visible stones below the common iliac vessels. 3) Tamsulosin was administrated in the treatment group, while nifedipine was administrated in the control group. The daily dose of tamsulosin was $0.4 \mathrm{mg}$ or $0.2 \mathrm{mg}$, and the dose of nifedipine was $30 \mathrm{mg}$ or $20 \mathrm{mg}$; besides, patients in both groups were encouraged to take plenty of fluids. 4) Outcome measures were expulsion rate, expulsion time, and complications. Reviews, animal studies, case series, retrospective comparative studies, and studies that did not adopt MET were excluded. After a preliminary review of the abstracts, final inclusion of a potential RCT was confirmed by a further full-text evaluation.

\section{Data extraction and methodological quality assessment}

After inclusion, another two reviewers (GZL and JWW) separately extracted the information, including study characteristics, data of outcome measures, and methodological items, from each article. 1) Study characteristics were first author, publication year, cases in each group, sex and average age of patients, interventions, stone size, follow-up, and other specific treatments and requirements. 2) Outcome measures included expulsion rate, expulsion time, and complications. 3) Methodological items were randomization, allocation concealment, blinding of participant and outcome assessment, incomplete outcome data, selective reporting result, and other potential biases. ${ }^{23}$ All the aforementioned information was cross-checked, and any disagreement was solved through discussion.

\section{Statistical analysis}

Review Manager (RevMan 5.3; Cochrane Collaboration, Copenhagen, Denmark) was used to analyze the pooled data. The overall effect of dichotomous data was presented by risk ratios (RRs), and continuous variables were presented by standard mean difference. Their respective $95 \%$ confidence intervals (CIs) were provided to show the probable size of interval. Significant difference was considered when a $P$-value was $<0.05$. Subgroup analysis was performed to identify the important clinically related items, and the statistical heterogeneity across studies was tested by chi-square statistic and presented by the $P^{2}$-value. A homogeneity was considered when $I^{2}<50 \%$, and in this case, a fixed-effects model was adopted. Otherwise, a heterogeneity was considered, and a random-effects model was adopted to provide a relatively conservative estimate; meanwhile, sensitivity analysis was performed to investigate the source of heterogeneity and the consistency of the result. An inverted funnel plot was used to assess the risk of publication bias. 
This meta-analysis was reported according to the Preferred Reporting Items for Systematic Reviews and MetaAnalyses. ${ }^{24}$

\section{Results}

\section{Study characteristics and methodological quality}

Finally, a total of 12 RCTs were selected from the primary 273 abstracts in the meta-analysis (Figure 1). The meta-analysis consisted of 4,961 patients with DUC, of whom 2,489 cases were in the tamsulosin group and 2,472 cases were in the nifedipine group. The basic characteristics of the included RCTs are listed in Table 1. The average age ranged from 30.7 to 47.9 years. The location of calculi was distal urinary tract in most studies; besides, two studies enrolled patients with both lower and upper urinary tract calculi. ${ }^{15,21}$ Ten RCTs only administrated MET with tamsulosin and nifedipine, and two studies administrated MET combined with ESWL. ${ }^{14,15}$ The average size of calculi was also presented, and although the average size ranged from $4.7 \mathrm{~mm}$ to $10 \mathrm{~mm}$, there were no significant differences between the groups as stated in each study. The dose of tamsulosin was $0.4 \mathrm{mg} / \mathrm{d}$, except for one study, which adopted a dose of $0.2 \mathrm{mg} / \mathrm{d},{ }^{14}$ and the dose of nifedipine was $30 \mathrm{mg} / \mathrm{d}$ except for three studies, which adopted a dose of $20 \mathrm{mg} / \mathrm{d} \cdot{ }^{15,17,18}$ In both groups, patients orally took the drugs with a maximum duration of 28 days until the expulsion of calculi with sufficient fluid $(\geq 2 \mathrm{~L} / \mathrm{d})$ intake.

The result of methodological quality assessment is shown in Figure 2. The overall quality was good, except one trial, which did not adopt blinding, ${ }^{16}$ and nine trials, which did not report allocation concealment. ${ }^{11-14,17-20,22}$

\section{Expulsion rate}

All trials reported the data of expulsion rate after treatment. There was a heterogeneity across the trials $\left(I^{2}=82 \%\right)$, and the results of the meta-analysis in a random-effects model showed that tamsulosin achieved a higher success rate than nifedipine (90.2\% vs $72.8 \%$, RR $=1.21,95 \%$ CI [1.09, 1.34], $P=0.0002)$. Sensitivity analysis showed that the heterogeneity was significantly decreased $\left(I^{2}=29 \%\right)$ after omitting one trial, 21 and the meta-analysis in a fixed-effects model demonstrated the superiority of tamsulosin to nifedipine in the aspect of expulsion rate (92.9\% vs $71.4 \%, \mathrm{RR}=1.29,95 \%$ CI $[1.25,1.33], P<0.0001)$, as shown in Figure 3.

\section{Expulsion time}

Six trials reported the data of expulsion time. ${ }^{13,15,17,18,20,21}$ There was a heterogeneity across the trials $\left(I^{2}=74 \%\right)$, and the results of meta-analysis in a random-effects model indicated that tamsulosin also led to a shorter expulsion time than nifedipine ( standard mean difference $=-0.39,95 \%$ CI $[-0.72,-0.05]$, $P=0.02)$. Sensitivity analysis showed that the heterogeneity could not be eliminated by omitting one or more of the trials, prompting that some kinds of characteristics might influence the expulsion time (Figure 4).

\section{Complications}

Seven trials presented the incidence of complications related to treatment. ${ }^{12,15,17-21}$ Without a statistical heterogeneity

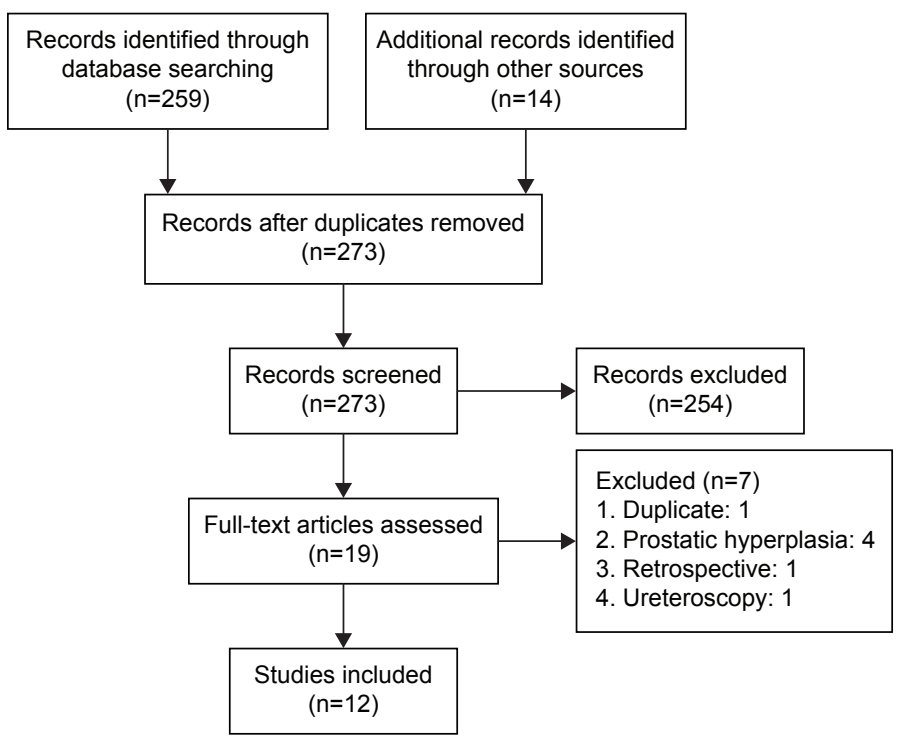

Figure I Flowchart of literature selection process. 
Table I Characteristics of the included RCTs

\begin{tabular}{|c|c|c|c|c|c|c|c|c|}
\hline \multirow[t]{2}{*}{ Study } & \multirow{2}{*}{$\begin{array}{l}\text { Case } \\
(\mathrm{T} / \mathrm{C})\end{array}$} & \multirow[t]{2}{*}{ Age (T/C, years) } & \multicolumn{2}{|c|}{$\operatorname{Sex}(M / F)$} & \multirow{2}{*}{$\begin{array}{l}\text { Intervention } \\
\text { (T/C) }\end{array}$} & \multirow[t]{2}{*}{ Size $(\mathrm{T} / \mathrm{C}, \mathrm{mm})$} & \multirow{2}{*}{$\begin{array}{l}\text { Follow- } \\
\text { up }\end{array}$} & \multirow{2}{*}{ Others } \\
\hline & & & $\mathbf{T}$ & C & & & & \\
\hline $\begin{array}{l}\text { Porpiglia } \\
\text { et al" }\end{array}$ & $28 / 30$ & NR & NR & & $\mathrm{TA} /$ nifedipine $30 \mathrm{mg}$ & $5.42 / 4.7$ & 4 weeks & $\begin{array}{l}\text { Deflazacort } 30 \mathrm{mg} \text { for all } \\
\text { patients }\end{array}$ \\
\hline $\begin{array}{l}\text { Dellabella } \\
\text { et al }{ }^{12}\end{array}$ & $70 / 70$ & $43.8 \pm|3.9 / 4| .8 \pm 15.4$ & $54 / 16$ & $51 / 19$ & $\mathrm{TA} /$ nifedipine $30 \mathrm{mg}$ & $7.2 \pm 2.4 / 6.2 \pm 1.5$ & 4 weeks & $\begin{array}{l}\text { Antibiotic prophylaxis or anti- } \\
\text { inflammatory drugs on demand }\end{array}$ \\
\hline Lü et $\mathrm{al}^{13}$ & $60 / 60$ & $38 \pm 13 / 34 \pm 13$ & $51 / 9$ & $42 / 18$ & $\mathrm{TA} /$ nifedipine $30 \mathrm{mg}$ & $7.0 \pm 2.0 / 7.0 \pm 2.0$ & 2 weeks & $\begin{array}{l}\text { Levofloxacin } 0.2 \mathrm{~g} \text { and } 2 \mathrm{~L} \text { of } \\
\text { water daily }\end{array}$ \\
\hline $\begin{array}{l}\text { Choi } \\
\text { et al }{ }^{14}\end{array}$ & $32 / 31$ & $47.9 \pm \mid 4.2 / 45.2 \pm I I . I$ & $25 / 7$ & $26 / 5$ & $\begin{array}{l}\text { TA } 0.2 \mathrm{mg} / \text { nifedipine } \\
30 \mathrm{mg}\end{array}$ & $7.6 \pm 1.5 / 7.3 \pm 1.3$ & 2 weeks & Patients underwent ESWL \\
\hline $\begin{array}{l}\text { Vicentini } \\
\text { et } \text { al }^{15}\end{array}$ & $38 / 35$ & $47.3 \pm 11.5 / 48.6 \pm 10.4$ & $16 / 22$ & $18 / 17$ & $\mathrm{TA} /$ nifedipine $20 \mathrm{mg}$ & $\begin{array}{l}10(5-20) / 10 \\
(5-20)\end{array}$ & 4 weeks & $\begin{array}{l}\text { Patients underwent ESWL and } \\
200 \mathrm{mg} \text { celecoxib, twice daily } \\
\text { on demand }\end{array}$ \\
\hline Ye et $\mathrm{al}^{16}$ & I,596/I,593 & $\begin{array}{l}30.7(18-48) / 34.5 \\
(22-50)\end{array}$ & $998 / 598$ & $989 / 604$ & $\begin{array}{l}\text { TA/Nifedipine } 30 \\
\mathrm{mg}\end{array}$ & $\begin{array}{l}5.8(4.0-7.0) / \\
5.6(4.2-6.9)\end{array}$ & 4 weeks & $\begin{array}{l}\text { Levofloxacin } 0.2 \mathrm{~g} \text { and } 2-2.5 \mathrm{~L} \\
\text { of water daily }\end{array}$ \\
\hline $\begin{array}{l}\text { Liao } \\
\text { et } \mathrm{al}^{17}\end{array}$ & $59 / 53$ & $34(19-49)$ & $58 / 54$ & & $\mathrm{TA} /$ nifedipine $20 \mathrm{mg}$ & $6.2 \pm 1.2 / 5.8 \pm 1.3$ & 4 weeks & $\begin{array}{l}\text { Quinolone antibiotics used and } \\
>2 L \text { of water daily }\end{array}$ \\
\hline $\begin{array}{l}\text { Islam } \\
\text { et al| }\end{array}$ & $32 / 31$ & $46.6 / 47.4$ & $20 / 12$ & $21 / 10$ & TA/nifedipine $20 \mathrm{mg}$ & $\begin{array}{l}5.9(3-10) / 6.0 \\
(3.5-10)\end{array}$ & 4 weeks & $\begin{array}{l}\text { Ciprofloxacin } 500 \mathrm{mg} \text {, twice a } \\
\text { day, and } 2.5 \mathrm{~L} \text { of hydration daily }\end{array}$ \\
\hline $\begin{array}{l}\text { Gandhi } \\
\text { and Agrawal }{ }^{19}\end{array}$ & $64 / 64$ & $34 \pm|2.8 / 30.4 \pm| \mid .36$ & $38 / 26$ & $36 / 28$ & $\mathrm{TA} /$ nifedipine $30 \mathrm{mg}$ & $8.6 \pm 2.3 / 8.9 \pm 2.5$ & 4 weeks & $\begin{array}{l}\text { Prednisolone } 30 \mathrm{mg} / \mathrm{d} \text { for } \\
10 \text { days and diclofenac } 75 \mathrm{mg} \\
\text { intramuscularly on demand }\end{array}$ \\
\hline $\begin{array}{l}\text { Balci } \\
\text { et a }{ }^{20}\end{array}$ & $25 / 25$ & $39.5 \pm|2.1 / 36.4 \pm| 1.5$ & $18 / 7$ & $17 / 8$ & $\mathrm{TA} /$ nifedipine $30 \mathrm{mg}$ & $7.1 \pm 1.5 / 6.4 \pm 1.1$ & 4 weeks & $\begin{array}{l}50 \mathrm{mg} \text { diclofenac sodium and } \\
2-2.5 \mathrm{~L} \text { of water daily }\end{array}$ \\
\hline $\begin{array}{l}\text { Pickard } \\
\text { et al }{ }^{21}\end{array}$ & $383 / 383$ & $43 . I \pm I I .5 / 42.3 \pm I I .0$ & $315 / 68$ & $317 / 66$ & $\mathrm{TA} /$ nifedipine $30 \mathrm{mg}$ & $4.6 \pm 1.6 / 4.5 \pm 1.6$ & 4 weeks & $\begin{array}{l}\text { The need for intervention was } \\
\text { agreed }\end{array}$ \\
\hline $\begin{array}{l}\text { Zhang } \\
\text { et al }{ }^{22}\end{array}$ & $102 / 97$ & $34.6 \pm 11.4 / 36.3 \pm 9.7$ & $63 / 29$ & $68 / 29$ & $\mathrm{TA} /$ nifedipine $30 \mathrm{mg}$ & $6.9 \pm 1.6 / 6.8 \pm 1.6$ & 4 weeks & $\begin{array}{l}75 \mathrm{mg} \text { diclofenac sodium and } \\
\text { analgesic therapy on demand }\end{array}$ \\
\hline
\end{tabular}

Notes: Data were presented as median (range) or mean \pm standard deviation. Location was distal mean/stones located in juxtavesical or intramural tract. ( $\mathrm{T})$ and $(\mathrm{C})$ represent the treatment and control group, respectively.

Abbreviations: ESWL, extracorporeal shock wave lithotripsy; F, female; M, male; NR, not reported; RCTs, randomized controlled trial; TA, tamsulosin 0.4 mg/d.

$\left(I^{2}=0 \%\right)$, the meta-analysis in a fixed-effects model showed that tamsulosin was associated with fewer complications than nifedipine ( $\mathrm{RR}=0.45,95 \% \mathrm{CI}[0.28,0.72], P=0.0008)$. In order to investigate the detailed difference, subgroup analyses according to two classifications were performed. 1) Subgroup analysis according to severity revealed that compared with nifedipine, tamsulosin induced a lower incidence of both mild $\left(I^{2}=33 \%\right.$, RR $=0.48,95 \%$ CI $\left.[0.28,0.84], P=0.009\right)$

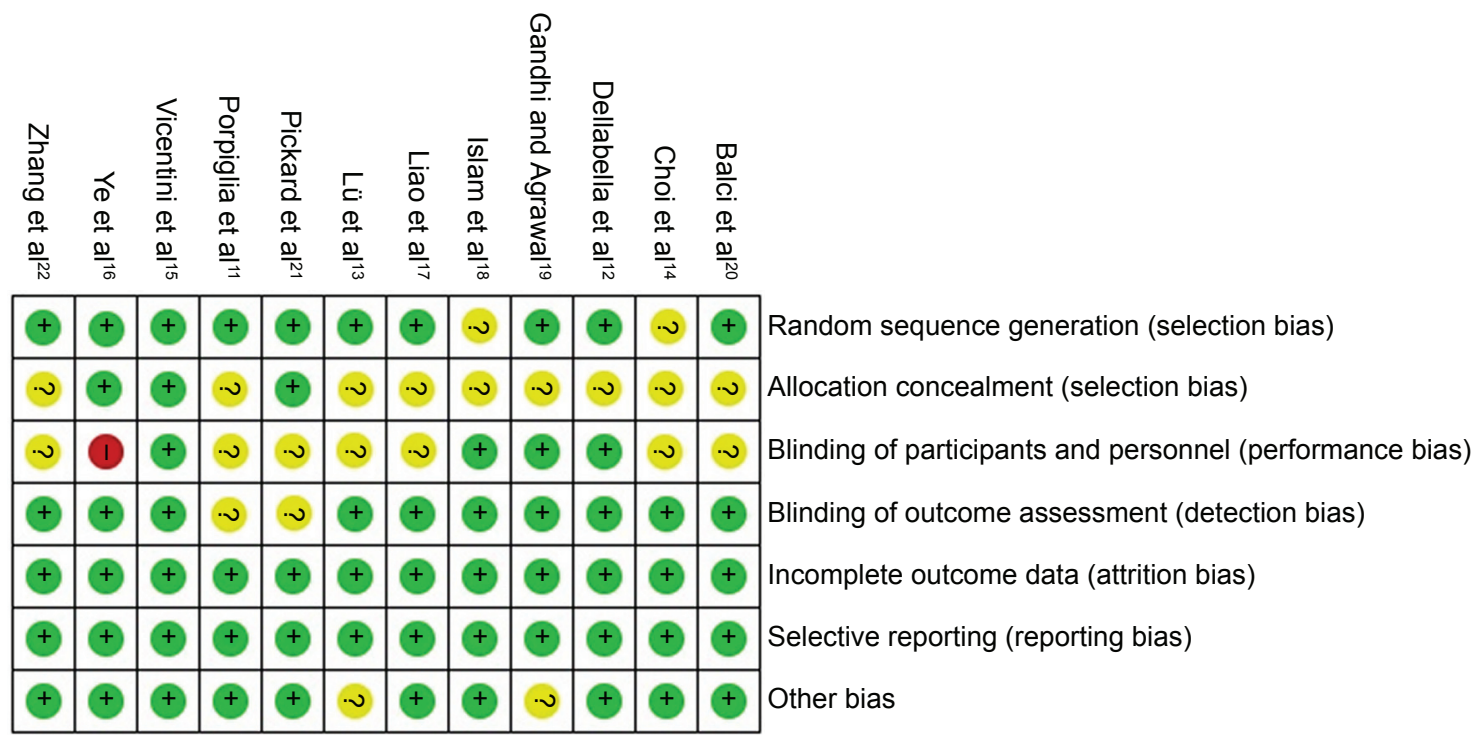

Figure 2 Quality assessment graph.

Note: (+) low risk, (?) unclear risk, (-) high risk. 


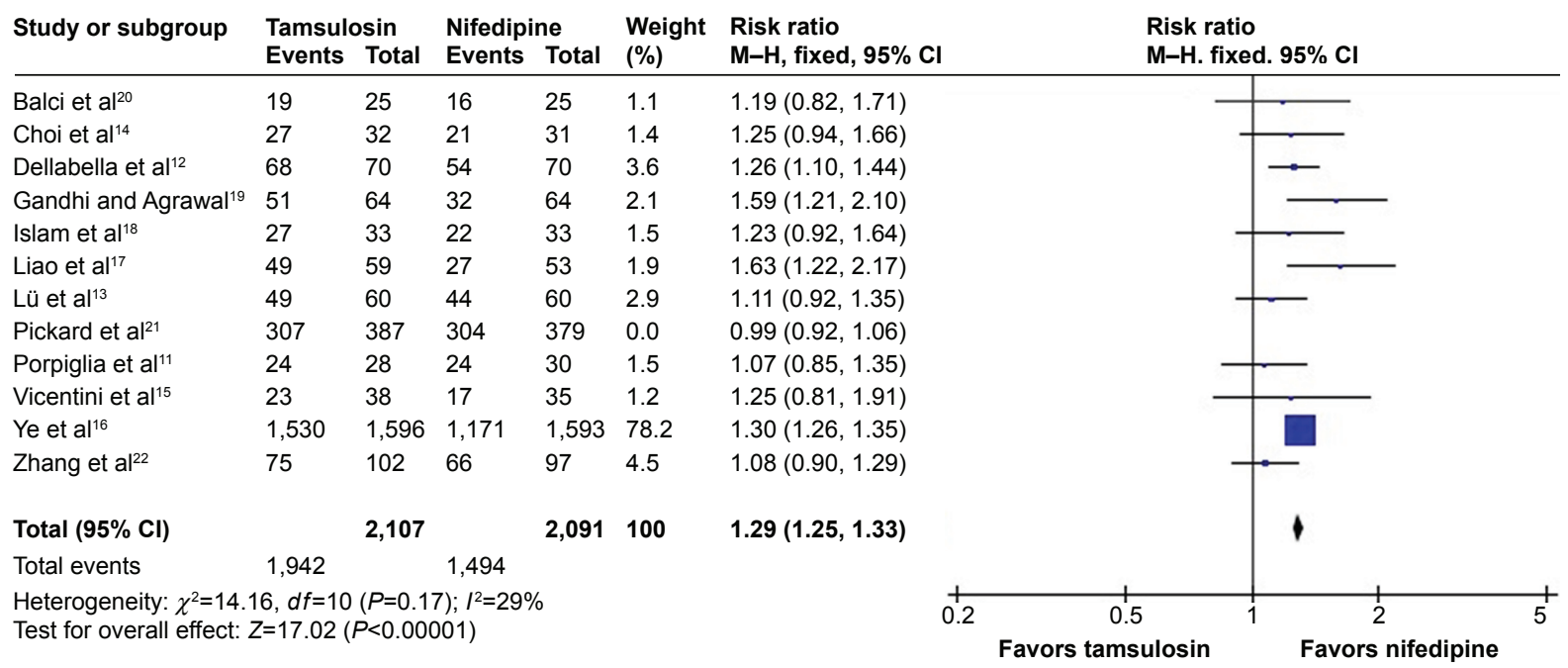

Figure 3 Meta-analysis results of expulsion rate between the groups.

Abbreviations: $d f$, degrees of freedom; $\mathrm{M}-\mathrm{H}$, Mantel Haenszel; $\mathrm{Cl}$, confidence interval.

and moderate-to-severe complications $\left(I^{2}=0 \%, \mathrm{RR}=0.39\right.$, $95 \%$ CI $[0.17,0.93], P=0.03$, as shown in Figure 5. 2) With decreased statistical test power, subgroup analysis according to specific diagnosis demonstrated a lesser incidence of diarrhea with tamsulosin than with nifedipine $(\mathrm{RR}=0.08,95 \%$ CI [0.02, 0.42], $P=0.003$ ), while no significant differences in dizziness, gastric upset, hypotension, emergency hospitalization, headache, fatigue, and steinstrasse were found, as shown in Table 2 .

\section{Publication bias}

The shapes of inverted funnel plots indicated low risks of publication bias in the outcomes of expulsion rate (Figure 6) and complications.

\section{Discussion}

As reported, $\sim 70 \%$ of ureteral calculi were located in the lower third part of the urinary tract, called lower ureteral stone or DUC. ${ }^{22}$ Actually, nearly all DUC would be expelled spontaneously when $<4 \mathrm{~mm}$, and a DUC had a possible spontaneous expulsion rate of $25 \%-60 \%$ when its size was between $4 \mathrm{~mm}$ and $7 \mathrm{~mm} \cdot{ }^{25,26}$ Based on these findings, many efforts were made to find effective approaches to enhance the spontaneous expulsion. After a high volume of fluid intake, both the hydrostatic pressure and the volume of urine were significantly increased, while clinical evidence defined the potential effect of simply fluid intake on expulsion rate. ${ }^{27}$ For further understanding of local inflammatory reactions in ureteral obstruction, administration of nonsteroidal anti-inflammatory drugs was attempted to decrease ureteral contractions, although no significant difference was achieved. ${ }^{28}$ Since the first report by Borghi et al showing an increasing rate of spontaneous stone expulsion through MET, ${ }^{29,30}$ various agents have been studied. So far, alpha-receptor blocker and calcium-channel blocker were the most promising agents for DUC in MET, and as the typical drugs, the comparative efficacy of tamsulosin and nifedipine was systematically evaluated in order to provide evidence for clinical choice and decision.

In this critical meta-analysis, 12 RCTs consisting of 4,961 patients were pooled analyzed. The results demonstrated

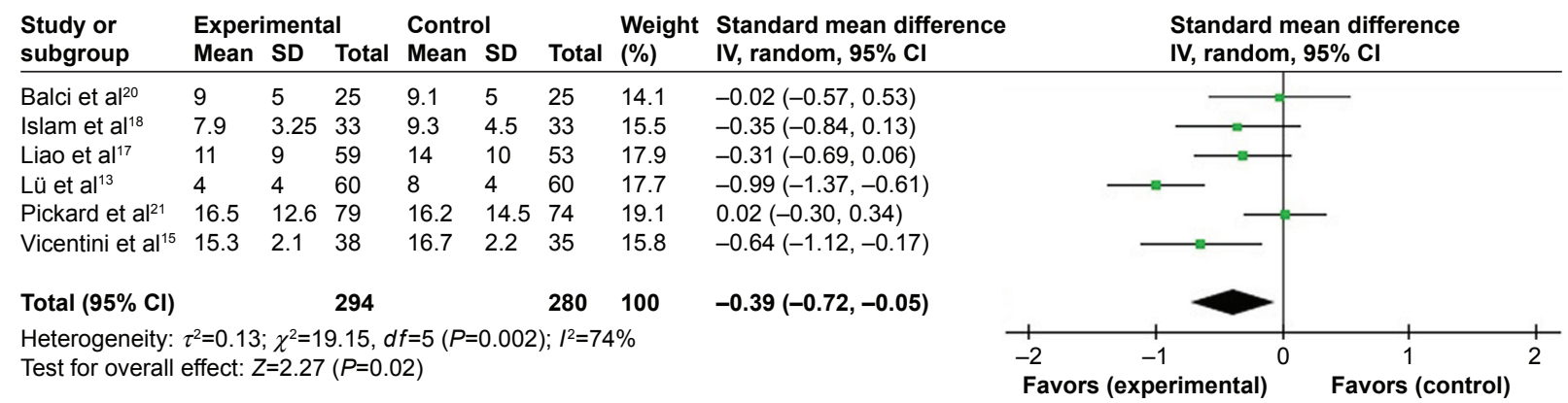

Figure 4 Meta-analysis results of expulsion time between the groups.

Abbreviations: $\mathrm{Cl}$, confidence interval; $d f$, degrees of freedom; SD, standard deviation; IV, inverse variance. 


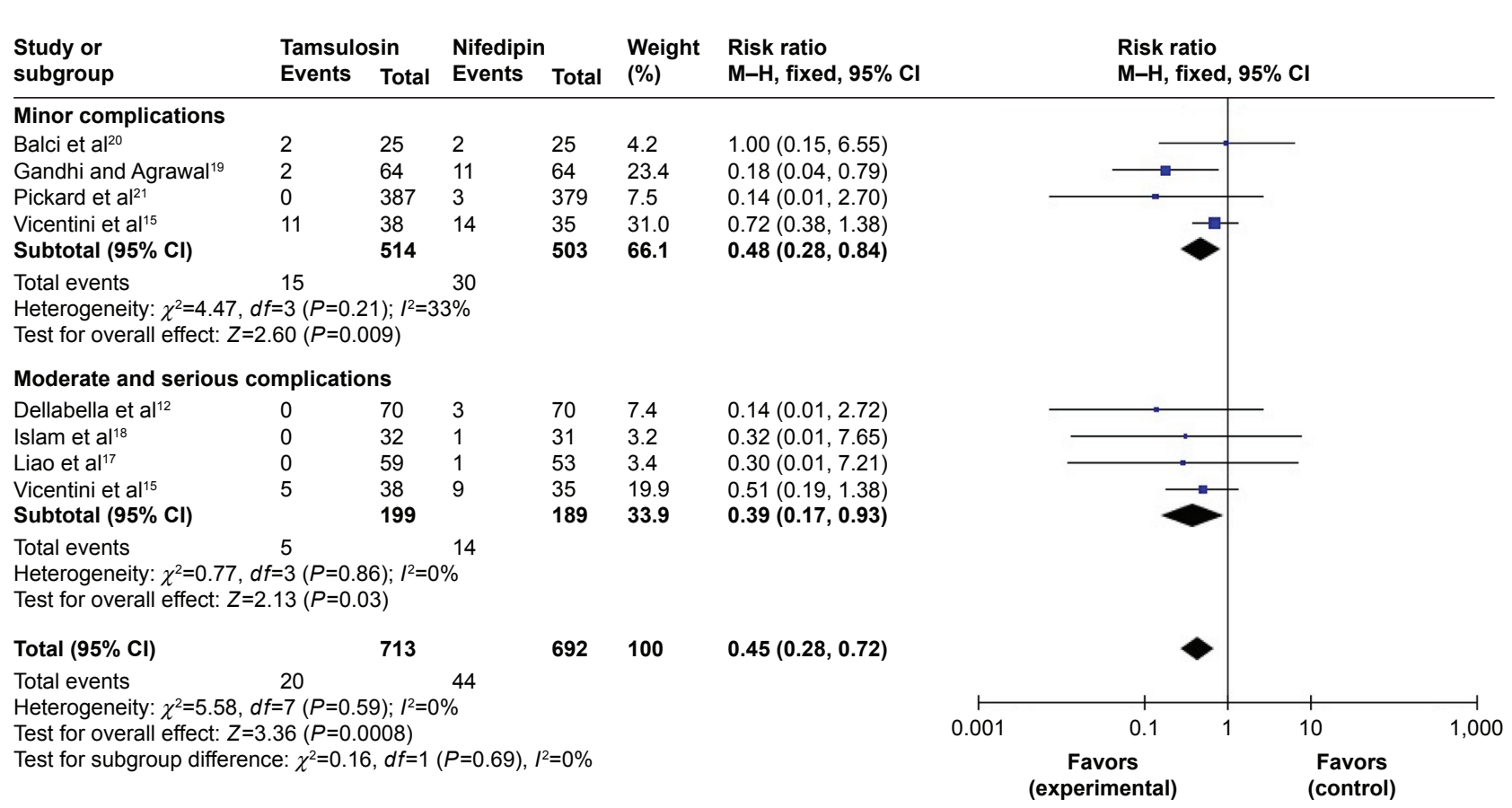

Figure 5 Meta-analysis results of complications between the groups.

Abbreviations: $\mathrm{Cl}$, confidence interval; df, degrees of freedom; $\mathrm{M}-\mathrm{H}$, Mantel Haenszel.

that tamsulosin significantly increased the expulsion rate $(\mathrm{RR}=1.29)$ of DUC by $<10 \mathrm{~mm}$ when compared with nifedipine. The inverted funnel plot showed that the result was stable and reliable. To determine the expulsion of calculi, patients were advised to take plenty of fluid and filter their urine and were checked by at least physical examination, plain abdominal X-rays, or abdominal ultrasonography weekly or biweekly. A recent multicenter RCT conducted in the $\mathrm{UK}^{22}$ stated that there was no significant difference between tamsulosin and nifedipine and both of the two drugs were not effective at decreasing the need of treatment in 4 weeks. However, the conclusion should be considered carefully because of the location and size of calculi, which were very most important factors used to predict the prognosis in the clinic. First, the study randomized 1,167 participants including not only DUC but also middle and upper ureteral calculi.
Although, the application of MET is gradually expanded to some kinds of indications when combined with ESWL for not only treating but also preventing calculi, ${ }^{14,15,31}$ a single effect of MET may be very limited, especially when applied to a location other than lower ureter. ${ }^{30}$ Second, the study included patients aged 18-65 years, and $75 \%$ of them suffered with stone $<5 \mathrm{~mm}$. Previous studies had already noticed this phenomenon that this size of stone would affect the evaluation of MET due to the bias of high incidence of spontaneous expulsion. ${ }^{32,33}$ Sensitivity analysis also revealed that the heterogeneity was mainly coming from the different stone sizes that all the trials had reported where patients had ureteral calculi $>5 \mathrm{~mm}$, except for Pickard et al. ${ }^{21}$

Besides, the optimal doses of tamsulosin and nifedipine were still unclear. Only one study compared $0.4 \mathrm{mg}$ and $0.2 \mathrm{mg}$ tamsulosin ${ }^{34}$ and found no significant difference and

Table 2 Subgroup analysis according to diagnosis of complications

\begin{tabular}{|c|c|c|c|c|c|c|}
\hline \multirow[t]{2}{*}{ Diagnosis } & \multicolumn{2}{|l|}{ Case $(n / N)$} & \multirow[t]{2}{*}{$I^{2}(\%)$} & \multirow[t]{2}{*}{ Model } & \multirow[t]{2}{*}{$\mathbf{R} \mathbf{R}$} & \multirow[t]{2}{*}{$P$-value } \\
\hline & Tamsulosin & Nifedipine & & & & \\
\hline Dizziness & $24 / 127$ & $13 / 124$ & 80 & Random effects & $2.08(0.32,13.36)$ & 0.44 \\
\hline Gastric upset & $16 / 476$ & $2 / 468$ & 73 & Random effects & $\mathrm{I} .64(0.06,47.99)$ & 0.77 \\
\hline Diarrhea & $0 / 476$ & $17 / 468$ & 0 & Fixed effects & $0.08(0.02,0.42)$ & 0.003 \\
\hline Hypotension & $0 / 91$ & $2 / 84$ & 0 & Fixed effects & $0.31(0.03,2.93)$ & 0.31 \\
\hline Emergency & $5 / 108$ & $12 / 105$ & 0 & Fixed effects & $0.4 \mathrm{I}(0.16,1.05)$ & 0.06 \\
\hline Headache & $32 / 451$ & $29 / 443$ & 0 & Fixed effects & I.IO (0.76, I.59) & 0.61 \\
\hline Fatigue & $3 / 64$ & $0 / 64$ & - & - & $7.0(0.37,132.83)$ & 0.20 \\
\hline Steinstrasse & $5 / 38$ & $4 / 35$ & - & - & I.I5 $(0.34,3.95)$ & 0.82 \\
\hline
\end{tabular}

Abbreviation: RR, risk ratio. 


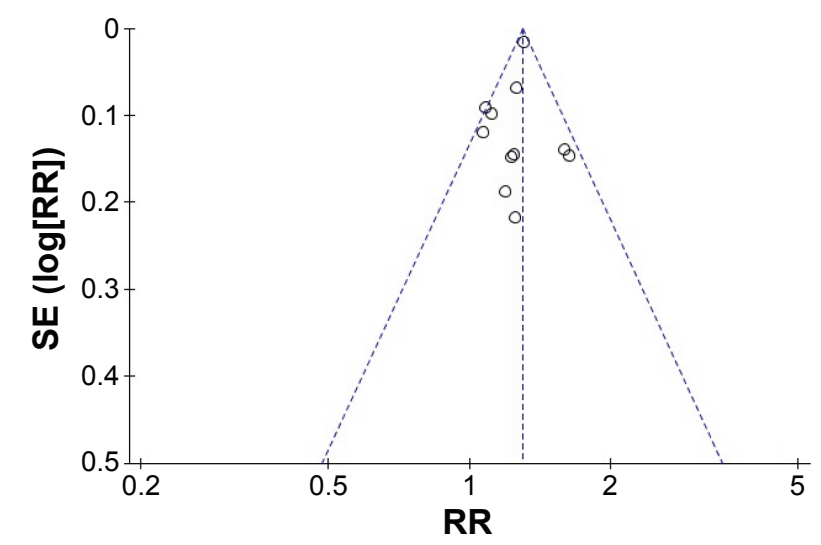

Figure 6 Inverted funnel plot investigating publication bias. Abbreviations: RR, risk ratio; SE, standard error.

supposed that both of them were sufficient to lower ureteral peristalsis. In fact, the investigation of dose of nifedipine seemed to be more practical that it was relatively contraindicated because of an increased risk in relation to myocardial infarction, cancer, and gastrointestinal hemorrhage in the elderly. ${ }^{35,36}$ Unfortunately, no relevant studies were found that directly compared the doses of $20 \mathrm{mg}$ and $30 \mathrm{mg}$ for nifedipine in MET. Regarding safety, the meta-analysis showed that tamsulosin had a total complication incidence of $0.8 \%$ and nifedipine had $1.8 \%$. Although both were very rare, tamsulosin still successfully reduced the incidence of both mild and moderate-to-severe complications when compared with nifedipine. The urgent complications of nifedipine mainly included emergency hospitalization of pain and hypotension.

Tamsulosin also achieved a faster expulsion time than nifedipine, and this may induce a reduction in both mean pain episode and analgesic requirement. However, Pickard et al ${ }^{21}$ reported the data and showed no significant difference as the number of days taken for pain medication was $11.6 \pm 8.7$ days with tamsulosin and $10.7 \pm 9$ days with nifedipine $(P=0.50)$; Balci et $\mathrm{al}^{20}$ and Ye et $\mathrm{al}^{16}$ reported that the average analgesic consumption of tamsulosin and nifedipine was $544 \mathrm{mg}$ vs $602 \mathrm{mg}(P=0.98)$ and $52.35 \mathrm{mg}$ vs $109.33 \mathrm{mg}(P<0.01)$, respectively. These biases might be caused by the different tolerance rates of pain and the severity of obstruction among the patients.

To explain the distinct difference between the two drugs, basic studies have provided us with some potentially underlying mechanisms, including the predominant relaxant effects based on ureteral segment and drug dosage. Smooth muscle contraction is directly caused by an increased calcium concentration, which is caused by two main pathways, including extracellular calcium transport and intracellular storage release. ${ }^{37}$ Under the condition of spontaneous contractility, ureteric muscle has a baseline frequency, interval, and amplitude of contraction and thus induces a persistent ureteric pressure. An in vivo human study showed that tamsulosin reduced the pressure generation and maintained the baseline frequency in the proximal ureter, while nifedipine seemed to have conflicting effects on contraction frequency and inconsistent ureteric pressure response. ${ }^{38}$ However, an animal study stated that tamsulosin increased the interval by $27 \%$ and decreased the amplitude by $7 \%$ in the distal ureter and nifedipine blocked all contractile activities. ${ }^{37}$ Although both the amplitude and pressure were decreased, tamsulosin and nifedipine were supposed to have distinctly different effects on different ureteral segments. A further study indicated that blockade of 5-methylurapidil would decrease muscle tone by $47 \%$ in the proximal and by $65 \%$ in the distal ureter and nifedipine would decrease muscle tone by $5 \%$ in the proximal and by $33 \%$ in the distal ureter. ${ }^{39}$ The different effects were demonstrated to be dose dependent, such that in all segments, $>10^{-6} \mathrm{M}$ in tamsulosin, or $10^{-7} \mathrm{M}$ in nifedipine, can absolutely block all contractile activities. $^{40}$

Implications for clinical practice and limitation of the meta-analysis should be mentioned. In fact, ureteroscopy would be the most valuable treatment for DUS $<10 \mathrm{~mm}$ for a long time due to its high success rate. ${ }^{41}$ However, when applied to appropriate patients with certain predictive parameters as well as their willingness, ${ }^{42}$ MET, especially tamsulosin, provided a promising opportunity of expelling stones without high invasion and expensive cost, especially when combined with ESWL and other minimally invasive procedures. Besides, it would never influence the further possible surgeries and also would prevent recurrence. ${ }^{31}$ However, the translation of clinical science into practice still needs more time. ${ }^{43}$ Limitations were as follows: 1) Participant blinding was hard to realize due to the different usage of the drugs. As outcomes were objectively measured, it would not alert current results. 2) One trial adopted a dose of $0.2 \mathrm{mg}$ for tamsulosin, and three trials adopted a dose of $20 \mathrm{mg}$ for nifedipine. ${ }^{14,15,17,18}$ Although comparable in each trial and handled by sensitivity analysis, this might still induce a heterogeneity across the trials. And the optimal dose of drugs, especially nifedipine, warranted more researches. 3) Two trials performed a ESWL before MET, and this might induce a little higher expulsion rate in both groups. 4) Stone size had a potential influence on clinical efficacy in MET, and Pickard et $\mathrm{al}^{21}$ included patients with an average stone size $<5 \mathrm{~mm}$ as mentioned earlier. 5) Although a comprehensive search was 
conducted, publication biases may exist as positive studies seemed easier to be published.

\section{Conclusion}

In conclusion, tamsulosin showed an overall superiority to nifedipine for DUC $<10 \mathrm{~mm}$ in aspects of expulsion rate, expulsion time, and safety. Tamsulosin was supposed to be the first drug to be recommended to patients willing to receive MET.

\section{Disclosure}

The authors report no conflicts of interest in this work.

\section{References}

1. Bartoletti R, Cai T, Mondaini N, et al. Epidemiology and risk factors in urolithiasis. Urol Int. 2007;79(suppl 1):3-7.

2. Moe OW. Kidney stones: pathophysiology and medical management. Lancet. 2006;367(9507):333-344.

3. Ahlstrand C, Tiselius HG. Recurrences during a 10-year follow-up after first renal stone episode. Urol Res. 1990;18(6):397-399.

4. Brown J. Diagnostic and treatment patterns for renal colic in US emergency departments. Int Urol Nephrol. 2006;38(1):87-92.

5. Moe OW, Pearle MS, Sakhaee K. Pharmacotherapy of urolithiasis: evidence from clinical trials. Kidney Int. 2011;79(4):385-392.

6. Li M, Wang Z, Yang J, et al. Adjunctive medical therapy with a-blocker after extracorporeal shock wave lithotripsy of renal and ureteral stones: a meta-analysis. PLoS One. 2014;10(4):e0122497.

7. Campschroer T, Zhu Y, Duijvesz D, Grobbee DE, Lock MT. Alphablockers as medical expulsive therapy for ureteral stones. Cochrane Database Syst Rev. 2014;4:CD008509.

8. Cao D, Yang L, Liu L, et al. A comparison of nifedipine and tamsulosin as medical expulsive therapy for the management of lower ureteral stones without ESWL. Sci Rep. 2014;4(22):5254.

9. Preminger GM, Tiselius HG, Assimos DG, et al; American Urological Association Education and Research, Inc; European Association of Urology. 2007 Guideline for the management of ureteral calculi. Eur Urol. 2007;52(6):1610-1631.

10. Seitz C, Liatsikos E, Porpiglia F, Tiselius HG, Zwergel U. Medical therapy to facilitate the passage of stones: what is the evidence? Eur Urol. 2009;56(3):455-471.

11. Porpiglia F, Ghignone G, Fiori C, Fontana D, Scarpa RM. Nifedipine versus tamsulosin for the management of lower ureteral stones. $J$ Urol. 2004;172(2):568-571.

12. Dellabella M, Milanese G, Muzzonigro G. Randomized trial of the efficacy of tamsulosin, nifedipine and phloroglucinol in medical expulsive therapy for distal ureteral calculi. J Urol. 2005;174(1):167-172.

13. Lü JJ, Wei LJ, Zhang H, et al. Comparison of tamsulosin versus nifedipine for the management of lower ureteral stones. Chin J Urol. 2006;27(9):612-614. [in Chinese].

14. Choi NY, Ahn SH, Han JH, Jang IH. The effect of tamsulosin and nifedipine on expulsion of ureteral stones after extracorporeal shock wave lithotripsy. Korean J Urol. 2008;49(2):150-154.

15. Vicentini FC, Mazzucchi E, Brito AH, Chedid Neto EA, Danilovic A, Srougi M. Adjuvant tamsulosin or nifedipine after extracorporeal shock wave lithotripsy for renal stones: a double blind, randomized, placebocontrolled trial. Urology. 2011;78(5):1016-1021.

16. Ye Z, Yang H, Li H, et al. A multicentre, prospective, randomized trial: comparative efficacy of tamsulosin and nifedipine in medical expulsive therapy for distal ureteric stones with renal colic. BJU Int. 2011;108(2): 276-279.
17. Liao ZM, Wang C, Chen Z, Ye ZQ. Comparison of therapeutic effect of tamsulosin and nifedipine in treatment of distal ureteral calculus. Mod J Integr Tradit Chin West Med. 2011;20(9):1046-1050.

18. Islam MS, Islam MW, Hooda MN, Alam A, Chowdhury GM, ShameemIA. The comparison and efficacy of nifedipine and tamsulosin for the management of lower ureteric stones. Bangladesh J Urol. 2012;13(1): $5-9$.

19. Gandhi HR, Agrawal C. The efficacy of tamsulosin vs. nifedipine for the medical expulsive therapy of distal ureteric stones: a randomised clinical trial. Arab J Urol. 2013;11(4):405-410.

20. Balci M, Tuncel A, Aydin O, et al. Tamsulosin versus nifedipine in medical expulsive therapy for distal ureteral stones and the predictive value of Hounsfield unit in stone expulsion. Ren Fail. 2014;36(10): 1541-1544.

21. Pickard R, Starr K, Maclennan G, et al. Medical expulsive therapy in adults with ureteric colic: a multicentre, randomised, placebo-controlled trial. Lancet. 2015;386(9991):341-349.

22. Zhang MY, Ding ST, Lü JJ, Zhang H, Xia QH. Comparison of tamsulosin with extracorporeal shock wave lithotripsy in treating distal ureteral stones. Chin Med J. 2009;122(7):798-801.

23. Higgins JPT, Green S [homepage on the Internet]. Cochrane Handbook for Systematic Reviews of Interventions Version 5.1.0. Cochrane Collaboration [updated March 2011]. Available from www.cochranehandbook.org. Accessed October 20, 2015.

24. Moher D, Liberati A, Tetzlaff J, Altman DG; PRISMA Group. Preferred reporting items for systematic reviews and meta-analyses: the PRISMA statement. Int J Surg. 2010;8(5):336-341.

25. Gravas S, Tzortzis V, Karatzas A, Oeconomou A, Melekos MD. The use of tamsulosin as adjunctive treatment after ESWL in patients with distal ureteral stone: do we really need it? Urol Res. 2007;35(5):231-235.

26. Coll DM, Varanelli MJ, Smith RC. Relationship of spontaneous passage of ureteral calculi to stone size and location as revealed by unenhanced helical CT. AJR Am J Roentgenol. 2002;178(1):101-103.

27. Worster AS, Bhanich Supapol W. Fluids and diuretics for acute ureteric colic. Cochrane Database Syst Rev. 2012;2(2):CD004926.

28. Phillips E, Hinck BR, Makhlouf A, et al. Celecoxib in the management of acute renal colic: a randomized controlled clinical trial. Urology. 2009;74(5):994-999.

29. Borghi L, Meschi T, Amato F, et al. Nifedipine and methylprednisolone in facilitating ureteral stone passage: a randomized, double-blind, placebo-controlled study. J Urol. 1994;152(4):1095-1098.

30. Picozzi SC, Marenghi C, Casellato S, Ricci C, Gaeta M, Carmignani L. Management of ureteral calculi and medical expulsive therapy in emergency departments. J Emerg Trauma Shock. 2011;4(1):70-76.

31. Liu CC, Hsieh HM, Wu CF, et al. Long-term prescription of $\alpha$-blockers decrease the risk of recurrent urolithiasis needed for surgical intervention-a nationwide population-based study. PLoS One. 2015;10(4): e0122494.

32. Hermanns T, Sauermann P, Rufibach K, Frauenfelder T, Sulser T, Strebel RT. Is there a role for tamsulosin in the treatment of distal ureteral stones of $7 \mathrm{~mm}$ or less? Results of a randomised, double-blind, placebo-controlled trial. Eur Urol. 2009;56(3):407-412.

33. Pedro RN, Hinck B, Hendlin K, Feia K, Canales BK, Monga M. Alfuzosin stone expulsion therapy for distal ureteral calculi: a double-blind, placebo controlled study. J Urol. 2008;179(6):2244-2247.

34. Cha WH, Choi JD, Kim KH, Seo YJ, Lee K. Comparison and efficacy of low-dose and standard-dose tamsulosin and alfuzosin in medical expulsive therapy for lower ureteral calculi: prospective, randomized, comparative study. Korean J Urol. 2012;53(5):349-354.

35. Welk BK, Teichman JM. Pharmacological management of renal colic in the older patient. Drugs Aging. 2007;24(11):891-900.

36. Abernethy DR, Schwartz JB. Calcium-antagonist drugs. N Engl J Med. 1999;341(3):181-182.

37. Troxel SA, Jones AW, Magliola L, Benson JS. Physiologic effect of nifedipine and tamsulosin on contractility of distal ureter. J Endourol. 2006; 20(8):565-568. 
38. Davenport K, Timoney AG, Keeley FX Jr. Effect of smooth muscle relaxant drugs on proximal human ureteric activity in vivo: a pilot study. Urol Res. 2007;35(4):207-213.

39. Davenport K, Timoney AG, Keeley FX. A comparative in vitro study to determine the beneficial effect of calcium-channel and $\alpha 1$-adrenoceptor antagonism on human ureteric activity. BJU Int. 2006; 98(3):651-655.

40. Whan Lee J, Young Lee M, Young Seo I. In-vitro study on ureteral smooth muscle contractility with tamsulosin, nifedipine, and terpene mixture (Rowatinex). Minerva Urol Nefrol. 2015;67(2):91-96.
41. Kiraç M, Atkin MS, Biri H, Deniz N. Ureteroscopy: the first-line treatment for distally located ureteral stones smaller than $10 \mathrm{~mm}$. Urol J. 2014;10(4):1028-1034.

42. Sahin C, Eryildirim B, Kafkasli A, et al. Predictive parameters for medical expulsive therapy in ureteral stones: a critical evaluation. Urolithiasis. 2015;43(3):271-275.

43. Itano N, Ferlic E, Nunez-Nateras R, Humphreys MR. Medical expulsive therapy in a tertiary care emergency department. Urology. 2012; 79(6):1242-1246.

\section{Publish your work in this journal}

Drug Design, Development and Therapy is an international, peerreviewed open-access journal that spans the spectrum of drug design and development through to clinical applications. Clinical outcomes, patient safety, and programs for the development and effective, safe, and sustained use of medicines are a feature of the journal, which has also been accepted for indexing on PubMed Central. The manuscript management system is completely online and includes a very quick and fair peer-review system, which is all easy to use. Visit http://www.dovepress.com/testimonials.php to read real quotes from published authors.

Submit your manuscript here: http://www.dovepress.com/drug-design-development-and-therapy-journal 